\title{
Primum non nocere - the need for appropriate assessment before starting testosterone therapy
}

M Moriarty ${ }^{1}, K_{\text {Keeran }}^{2}$, E George ${ }^{1}$

${ }^{1}$ Imperial College London Diabetes Centre, Abu Dhabi, UAE ${ }^{2}$ Imperial College London, UK

The prescription of testosterone replacement has increased in recent years. Awareness of hypogonadism has spread among men particularly those with erectile dysfunction along with a belief that testosterone replacement will provide a cure of symptoms in all cases.

\section{Presentation January 2016}

- 41 year old Emirati male

- Married, 4 children

- $\mathrm{PHx}$

- Hypercholesterolaemia on diet

- Vitamin D deficiency on replacement

- Poliomyelitis in childhood

- Erectile dysfunction Jan 2014 - initial response to Tadalafil waned after 18 months

- Commenced on Testosterone Undecanoate (Nebido) by Urologist June 2015 following single total morning testosterone result of $3.89 \mathrm{nmol} / \mathrm{L}(8.64-29.0)$

- SHBG and Prolactin normal, no other investigations performed

\section{Management}

- Indication for testosterone replacement was unclear, Haematocrit was raised compared to pre-treatment value

- Despite adequate serum testosterone erectile dysfunction worsened off Tadalafil

- In discussion with patient testosterone replacement was discontinued in May 2016

- Remained on Tadalfil

- Regular review and measurement of testosterone / gonadotrophins
- Examination

- Left sided weakness and wasting both limbs

- Normal visual fields

- Laboratory Results

- Testosterone $11.26 \mathrm{nmol} / \mathrm{L}$

- Haemoglobin 168, Haematocrit 0.5

- Normal TFTs, IGF-1, SST, Prolactin

- Imaging

- US testes - bilateral hydrocoeles

- DEXA

$\begin{array}{llll}\text { - } & \text { Spine } & \mathrm{T}-2.4 & \mathrm{Z}-2.1 \\ \text { - } & \text { Left NOF } & \mathrm{T}-3.3 & \mathrm{Z}-2.5 \\ & \text { Right NOF } & \mathrm{T}-1.9 & \mathrm{Z}-1.1\end{array}$

- Attributed to disuse osteoporosis from polio, commenced on Alendronate

\section{Change in Testosterone and Gonadotrophins}
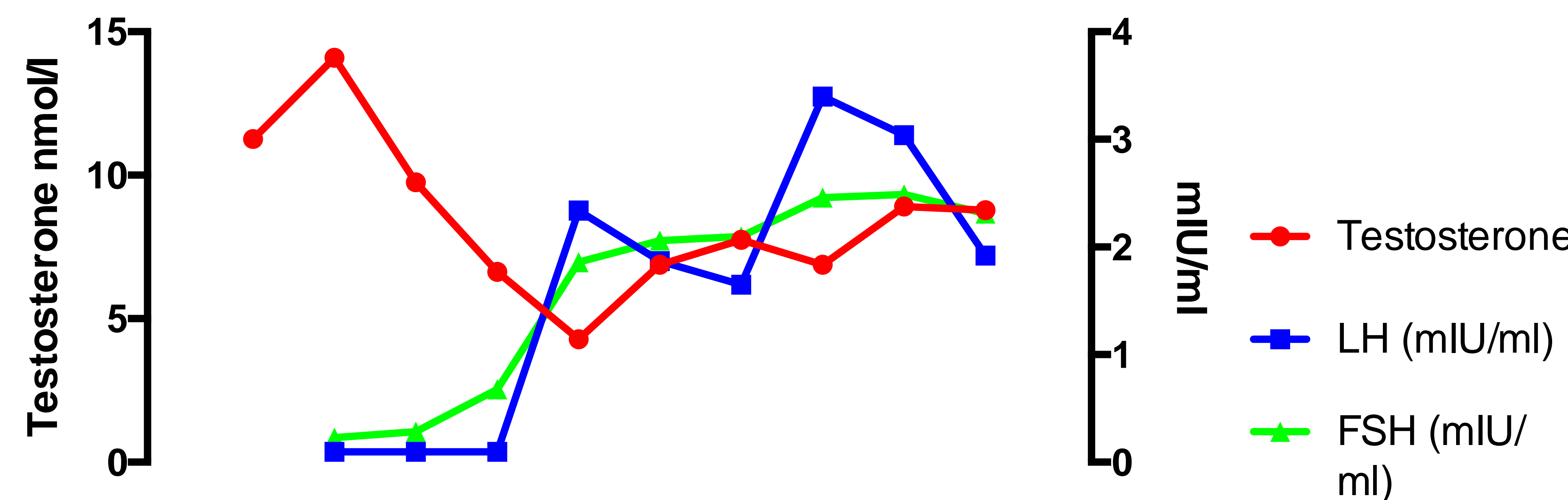

$\mathrm{ml})$

\begin{tabular}{|c|c|c|c|c|c|c|}
\hline Date & $\begin{array}{l}\text { Testosterone } \\
\text { (nmol/l) }\end{array}$ & $\begin{array}{c}\text { FAI (\%) } \\
(35-92.6)\end{array}$ & $\begin{array}{c}\text { LH } \\
(\mathrm{mlU} / \mathrm{ml}) \\
(1.7-8.6)\end{array}$ & $\begin{array}{c}\text { FSH } \\
(\mathrm{mlU} / \mathrm{ml}) \\
(1.5-12.4)\end{array}$ & $\begin{array}{c}\mathrm{Hb}(\mathrm{g} / \mathrm{L}) \\
(126-177)\end{array}$ & $\begin{array}{c}\text { Hct L/L } \\
(038-0.51)\end{array}$ \\
\hline $16 / 02 / 16$ & 11.26 & & & & & \\
\hline \multicolumn{7}{|c|}{ Testosterone last administered May 2016} \\
\hline $31 / 08 / 16$ & 14.1 & & $<0.1$ & 0.23 & 164 & 0.50 \\
\hline 21/09/16 & 9.75 & 45.7 & 0.1 & 0.285 & & \\
\hline 23/10/16 & 6.63 & 30.5 & 0.1 & 0.679 & & \\
\hline 22/11/16 & 4.29 & 18.7 & 2.34 & 1.86 & 158 & 0.47 \\
\hline 19/12/16 & 6.88 & 31.3 & 1.87 & 2.06 & & \\
\hline 16/01/17 & 7.75 & 32.6 & 1.65 & 2.10 & & \\
\hline 13/02/17 & 6.88 & 35.7 & 3.40 & 2.46 & 151 & 0.46 \\
\hline 08/05/17 & 8.92 & 39.68 & 3.04 & 2.49 & 146 & 0.44 \\
\hline 02/08/17 & 8.79 & 36.38 & 1.92 & 2.31 & 146 & 0.44 \\
\hline
\end{tabular}

\section{Outcome}

- 3 months after discontinuing testosterone replacement gonadotrophins remained suppressed.

- 6 months after discontinuation gonadotrophins remained suppressed and Free Androgen Index (FAI) had dropped to $18.7 \%$ with testosterone of $4.29 \mathrm{nmol} / \mathrm{L}$

- Recovery of testosterone and gonadotrophins has been sustained

- Symptoms of erectile dysfunction have resolved on Cialis

- DEXA will be repeated in 2018

\section{Discussion}

- Total testosterone levels alone have a poor specificity for the diagnosis of testosterone deficiency. A complete assessment should include SHBG (and a calculated FAI), LH and FSH and treatment initiation should be supervised by an endocrinologist.

- Trials of testosterone may have a placebo effect and suppress gonadotrophins. Withdrawal of testosterone in patients who take it inappropriately may result in transient low levels of testosterone. This may persist for several months and patients will need support through this period. The temptation to restart testosterone should be avoided.

- Correct identification and regular review of appropriate patients will ensure that testosterone therapy is offered to those who will benefit and avoided in those who are at risk of detrimental side effects. 